\title{
C-CBL E3 ubiquitin ligase expression increases across the spectrum of benign and malignant T-cell skin diseases
}

\author{
Katrin A. Salva, MD*, Margo J. Reeder, MD*, Rita Lloyd, MD*, and Gary S. Wood, MD ${ }^{*}$,** \\ *Department of Dermatology, University of Wisconsin, Madison, WI \\ ${ }^{*}$ William S. Middleton VA Medical Center, Madison, WI
}

\begin{abstract}
Prolonged survival of lesional T cells plays a central role in the pathogenesis of T-cell-mediated dermatoses. We have recently shown that the ubiquitin ligase c-CBL is highly expressed in cutaneous T-cell lymphoma (CTCL) and that its knockdown increases activation-induced cell death, a key pathway for T-cell apoptosis. Here, we extend our work on c-CBL expression in malignant $\mathrm{T}$ cells to their non-neoplastic counterparts in benign inflammatory dermatoses. Immunohistochemical staining with anti-c-CBL antibody was performed on lesional biopsies from a total of 65 patients with atopic dermatitis, allergic contact dermatitis, pityriasis rosea, psoriasis vulgaris, lichen planus, mycosis fungoides (MF)/Sézary syndrome (SS) as well as on tonsil tissue from 5 individuals and on 5 human cutaneous T-cell lymphoma cell lines. Protein levels were measured in situ using multispectral image analysis, a quantitative method that is $5 \mathrm{x}$ more sensitive than standard immunohistology for antigen detection. There was a significant $(\mathrm{p}<0.05)$ and progressive increase of mean c-CBL expression across the spectrum of inflammatory dermatoses (2-fold), MF/SS (3-fold) and lymphoma cell lines (4-fold) as compared to tonsillar T lymphocytes. A subset of MF/SS cases expressed mean c-CBL levels above the ranges observed in inflammatory dermatoses. Given our prior finding that c-CBL inhibits activation-induced cell death, c-CBL might play a role in the pathogenesis of inflammatory dermatoses and CTCL.
\end{abstract}

\section{Keywords}

T cells; CBL ligases; apoptosis; cutaneous T-cell lymphoma; inflammatory skin disorders

\section{Introduction}

T-cell-mediated skin disorders encompass a wide clinical spectrum, ranging from benign inflammatory dermatoses (BIDs) such as atopic dermatitis, allergic contact dermatitis and psoriasis vulgaris, to malignant entities, i.e. cutaneous T-cell lymphomas (CTCLs). A common denominator in the pathophysiology of these disorders is the prolonged survival of activated and/or neoplastic T lymphocytes in lesional skin [1-4]. Such cells frequently exhibit an impaired ability to undergo activation-induced cell death (AICD), a key pathway

Corresponding author: Gary S. Wood, University of Wisconsin, Department of Dermatology, 1 South Park Street, Floor 7, Madison WI 53715, Phone: 608-287-2620, Fax: 608-287-2676, gwood@ dermatology.wisc.edu.

Conflicts of interest: None to report. The abstract was presented at the 2016 meeting of the Society for Investigative Dermatology. 
for T-cell apoptosis and a major mechanism for the deletion of clonally expanded $\mathrm{T}$ cells after antigenic T-cell receptor (TCR) stimulation [2-6]. AICD utilizes the extrinsic (deathreceptor-induced) apoptotic pathway with predominant involvement of the death receptor/ ligand pair FAS/FAS ligand (FASL).

Normal resting T cells express moderate amounts of FAS, while FASL expression is virtually absent. Short-term TCR activation triggers an increase of FAS but not FASL, followed by intrinsic (mitochondrial) apoptosis due to cytokine deprivation upon antigen withdrawal, whereas chronic TCR engagement leads to upregulation of both FAS and FASL with subsequent AICD. In contrast, T cells with dysfunctional TCR signaling and/or defective apoptotic machinery can escape AICD and persist in situ, which results in continued production of harmful cytokines with sustained inflammation, increased risk of malignant transformation and diminished sensitivity to apoptosis-inducing therapies [1-6]. Thus, elucidating the molecular basis of AICD defects is essential for a better understanding of the pathogenesis of T-cell-mediated dermatoses, and sets the stage for the development of improved treatment strategies.

This is exemplified by the two most common forms of CTCL, mycosis fungoides (MF) and its variant, Sézary syndrome (SS). The neoplastic cells in tissues of MF/SS patients commonly fail to upregulate FAS and/or FASL, which results in lymphoaccumulation and resistance to apoptosis [7-12]. We have previously shown that in some cases FAS can be increased epigenetically by derepression of its promoter with methotrexate (MTX) $[9,10]$. Our recent study revealed that the E3 ubiquitin ligase c-CBL inhibits TCR-mediated signal transduction and AICD in CTCL [13].

C-CBL, a member of the highly conserved family of Casitas B-lineage Lymphoma proteins, is responsible for the internalization and degradation of numerous receptor tyrosine kinases [14-17]. Its role as a negative regulator of TCR signaling is well documented and involves the deactivation of TCR-associated Y kinases, which promote downstream signaling events following TCR engagement, such as the increased expression of inducible FASL [16-20]. We determined that c-CBL is highly expressed in CTCL and that its knockdown restores FASL expression, thereby promoting AICD [13]. This discovery, in the view of the paucity of data on c-CBL expression levels in cutaneous T-cell disorders, prompted us to extend our work on malignant $\mathrm{T}$ cells to their non-neoplastic counterparts, the activated $\mathrm{T}$ cells in benign dermatoses. Here, we evaluate c-CBL expression across a broad range of BIDs in comparison with secondary lymphoid tissue as well as MF/SS patient samples and human CTCL cell lines using multispectral imaging analysis, a quantitative method that is 5x more sensitive than standard immunohistology for antigen detection [21].

\section{Materials and methods}

\section{Cell lines}

Human CTCL cell lines derived from patients with MF (MyLa), SS (Hut78, SZ4, Se-Ax), and from the peripheral blood of a patient with an unspecified leukemic-stage CTCL (HH) were acquired as described previously and cultured in RPMI 1640 medium with $2 \mathrm{mM} \mathrm{L-}$ glutamine (Corning, Manassas, VA) [9, 10, 22-26]. 10\% Fetal bovine serum (Fisher 
Scientific, Pittsburgh, PA), $1 \mathrm{mM}$ sodium pyruvate (Corning) as well as $10 \mathrm{mM} 4-(2-$ hydroxyethyl)-1-piperazine-ethanesulfonic acid (Corning; HH and SZ4 only) were added to the media. The cells were washed with phosphate buffered saline (PBS), centrifuged and resuspended in agarose gel to create cell pellets, which were subsequently formalin-fixed and paraffin-embedded. Prior to immunohistochemical staining, $5 \mu \mathrm{m}$ thick sections were mounted on Superfrost Plus glass slides (Fisher Scientific).

\section{Patients and tissue samples}

In total, 65 formalin-fixed, paraffin-embedded biopsy specimens from 64 patients seen at the Department of Dermatology of the University of Wisconsin as well as at the William S. Middleton VA Medical Center in the years 2002 to 2015 were included in our study. All specimens were obtained with the approval of the Institutional Review Board and collected in a Health Insurance Portability and Accountability Act-compliant manner. All CTCL patients gave written informed consent. All other patient samples and tonsil tissue were obtained through the SDRC Experimental Cutaneous Pathology Core as de-identified specimens. The clinical diagnoses and available demographic data are summarized in Table 1. All MF/SS cases were CD3+4+.

\section{Immunohistochemistry (IHC)}

For the current study, immunohistochemical staining was performed with the anti-c-CBL antibody, clone 3B12 (Lifespan Biosciences, Seattle, WA). The MACH4 Universal horseradish peroxidase-polymer detection system (Biocare Medical, Concord, CA) and 3,3diaminobenzidine (DAB; Sigma-Aldrich, St. Louis, MO) were applied for protein visualization. All sections were counterstained with methylene blue (MB) (Sigma-Aldrich). Each staining series included an isotype-matched control using a mouse $\mathrm{IgG}_{1}$ monoclonal antibody (Abcam, Cambridge, MA).

\section{Multispectral imaging analysis (MIA)}

Quantitative IHC data and multispectral images were generated with the Nuance ${ }^{\circledR}$ system (Perkin Elmer, Waltham, MA). Multispectral 8-bit image cubes of relevant areas on each slide were acquired in bright field mode at 20nm intervals from 420 to $720 \mathrm{~nm}$, using a 20x objective lens and a full CCD frame at $1 \times 1$ binning (1360×1024 pixels). A spectral library containing the characteristic wavelength emission curves of MB and DAB was created by sampling pure spectra from tissue sections stained with single chromogens, i.e. MB only and $\mathrm{DAB}$ only. Blue and red pseudo-colors were assigned by the investigators to visualize MB and $\mathrm{DAB}$, respectively. Three representative areas per biopsy were chosen for analysis. The image cubes, initially shown as pseudo-colored composites of both blue and red, were unmixed into individual components by the Nuance 3.0.2 software version. Corresponding RGB (red-blue-green) images, i.e. images showing the immunostained tissue as it would appear viewed under a regular light microscope (LM), were captured for direct visual comparison. For quantitation of c-CBL expression, 50-340 lymphoid cells per biopsy (depending on the amount of infiltrate) were manually designated as regions of interest (ROIs). C-CBL expression in tonsils was assessed specifically in small lymphocytes of the paracortical CD3+ T-cell regions. Using the spectral library as reference, the system measured the amount of target signal (intensity of red pseudo-color) within each ROI, 
automatically converting spectral data into optical density (OD) units. Final data were displayed as average OD value/cell. Figure 1 shows examples of images of protein visualization with MIA. Statistical analysis was performed using the Student's t-test. Values $<0.05$ were considered statistically significant.

\section{Results}

C-CBL protein expression increases across the spectrum of reactive tonsil, benign inflammatory dermatoses (BIDs), cutaneous T-cell lymphoma (CTCL) lesions and CTCL cell lines. C-CBL expression by lymphoid cells in a total of 75 specimens (Table 1) was visualized and assessed using quantitative IHC with multispectral image analysis (MIA). Figures 2A-C show representative standard IHC images of c-CBL staining of tonsil (A), atopic dermatitis (B) and patch/plaque-stage mycosis fungoides (C), demonstrating that the increased protein expression in BIDs and in CTCL as compared to the tonsil tissue was discernible by routine light microscopy. Figures 2D-F show corresponding multispectral images of the immunostain, which were used to quantitate c-CBL expression in all samples. There was a significant $(\mathrm{p}>0.05)$ and progressive increase of $\mathrm{c}-\mathrm{CBL}$ expression across the spectrum of five clinically distinct BIDs (2-fold), MF/SS (3-fold) and CTCL cell lines (4fold) as compared to secondary lymphoid tissue represented by reactive tonsil (Figure 3).

C-CBL expression was similar within each group of disorders irrespective of clinical diagnosis, chronicity or lesion type. There was no statistically significant difference in cCBL expression levels among atopic dermatitis, contact dermatitis, pityriasis rosea, psoriasis vulgaris and lichen planus (Figure 4). Similarly, c-CBL expression did not differ significantly among the types of CTCLs (MF versus SS) or CTCL lesions (MF patches/ plaques vs MF tumors) (Figure 4).

A subset of MF/SS cases expressed c-CBL at levels that exceeded those observed in BIDs. In the majority of CTCL biopsies (11 of 18 cases), c-CBL levels exceeded an average OD value of 0.32 , whereas none of the 47 BID cases crossed this expression threshold (Figure $5)$.

\section{Discussion}

Growing evidence points to defective AICD in lesional T cells as an essential factor in the pathophysiology of T-cell-derived skin disorders, however, the underlying mechanisms remain poorly defined [2-4]. Our current study demonstrates that c-CBL, a protein recently shown by us to block AICD in CTCL [13], is overexpressed in BIDs and increases across the spectrum of benign and malignant T-cell-mediated dermatoses. Together, these data suggest a possible role for c-CBL in the pathogenesis of BIDs and CTCL.

C-CBL ubiquitinates - and thereby negatively modulates - a multitude of receptor and nonreceptor kinases that participate in various signaling pathways related to cell differentiation and apoptosis [14-17]. Generally, loss-of-function mutations and/or low protein expression result in uninhibited and prolonged kinase-initiated signaling upon receptor stimulation, which promotes enhanced cell proliferation, tumor growth and metastasis [27-29]. Somatic and/or germline c-CBL mutations have been identified in various myeloid malignancies, 
such as acute myeloid leukemia and juvenile myelomonocytic leukemia, in non-small cell lung cancer and breast cancer cells [27, 28, 30-35].

Our recent work demonstrates that CTCLs often highly express c-CBL at both the protein and messenger RNA levels, which probably results in an enhanced rather than diminished function of this ligase in neoplastic T cells [13]. This c-CBL hyperactivity may lead to increased ubiquitination of TCR-associated $\mathrm{Y}$ kinases, making them unavailable for activation upon TCR engagement and thereby disrupting TCR-mediated downstream signaling events such as FASL upregulation, which in turn blocks FAS-FASL-induced AICD, allowing CTCL cells to accumulate and persist in situ. This mechanism is supported by our finding that c-CBL knockdown results in up-regulation of multiple TCR downstream signaling events, FASL and AICD [13]. Combined with constitutive activation of NF-kappa B and other proliferative drivers in advanced CTCL [36], this apoptosis block could lead to the situation depicted in Figure 6. Normal T cells maintain a balance between TCR-induced apoptosis and proliferation (top panel), whereas the overactivity of both c-CBL and proliferative drivers in malignant $\mathrm{T}$ cells leads to diminished apoptosis and unchecked proliferation (middle panel). Blocking of c-CBL restores TCR-mediated AICD, which overcomes proliferation and might result in tumor clearance (bottom panel).

Our current findings suggest that this mechanism might be at least partially responsible for the lack of AICD and the consequent prolonged survival of activated T cells in BIDs. The excessive longevity of c-CBL-high $\mathrm{T}$ cells could render such cells susceptible to mutations, which might promote the evolution of CTCL. The molecular cause(s) of c-CBL overexpression in activated/malignant $\mathrm{T}$ cells have yet to be determined. Known mechanisms that regulate c-CBL include dephosphorylation by Src-homology-2-containing phosphatase- 1 and degradation through self-ubiquitination or ubiquitination by HECT (homologous to the E6-associated protein carboxyl terminus)-type E3 ligases [16, 37].

Whereas chronic inflammation represents a well-recognized risk factor for various lymphoid malignancies such as mucosa-associated lymphoid tissue lymphomas and chronic lymphocytic leukemia [38-40], the clinical link between inflammatory skin conditions and CTCL is less clear. Although the development of CTCLs in patients with pre-existing dermatitis has been the subject largely of case reports [41-48], other studies investigating the relationship between BIDs and cancer including lymphoma have shown contradictory results [49-58]. However, in a recent population-based cohort study, patients with psoriasis were 3.82 times more likely to develop CTCL, compared to 1.34 for any type of lymphoma [59]. The "mild psoriasis" group was 3.51 times more likely, while patients with "moderate-tosevere" disease showed a 9.25 times increased risk of CTCL. Notably, the risk of developing CTCL far surpassed that of any other malignancy including leukemia.

Although this is only an initial study, assessment of c-CBL expression may prove to have clinical utility. Since the majority of MF/SS cases in this study expressed c-CBL at mean levels above the ranges measured in BIDs, high c-CBL expression might aid in the recognition of some CTCL cases if these findings can be confirmed. Conversely, many BID cases showed mean c-CBL levels below the CTCL range while others overlapped with the CTCL range. It will be interesting to determine if these two BID groups are at different risk 
for the development of CTCL. In addition, correction of c-CBL overexpression in activated and/or neoplastic $\mathrm{T}$ cells might represent a novel therapeutic strategy for the management of T-cell-mediated skin disorders.

Finally, from a methodological perspective, our report highlights the advantages of MIA over conventional microscopy in assessing the levels of protein expression in immunostained skin sections. In addition to showing far greater sensitivity than simple microscopy in detecting low-level biomarker expression, MIA systems allow objective, computerized scoring of stain intensity on a continuous scale [21]. This attribute makes MIA ideally suited as a tool to quantitate proteins in tissue sections $[21,60,61]$.

\section{Acknowledgments}

Sources of funding: This study was supported in part by NIH grants CA206104 and AR066524, the University of Wisconsin Comprehensive Cancer Center (UWCCC) Dennis Swatek Family Fund, the Dr. Martin and Dorothy Spatz Charitable Foundation and Merit Review funding from the Department of Veterans Affairs (G. S. Wood) as well as UWCCC grant CA014520.

\section{References}

1. Akdis CA, Blaser K, Akdis M. Apoptosis in tissue inflammation and allergic disease. Curr Opin Immunol. 2004; 16:717-723. [PubMed: 15511663]

2. Wehrli P, Viard I, Bullani R, et al. Death receptors in cutaneous biology and disease. J Invest Dermatol. 2000; 115:141-8. [PubMed: 10951228]

3. Trautman A, Akdis M, Bröcker EB, et al. New insights into the role of T cells in atopic dermatitis and allergic contact dermatitis. Trends Immunol. 2001; 22:530-2. [PubMed: 11574260]

4. De Panfilis G. Activation-induced cell death: a special program able to preserve the homeostasis of the skin? Exp Dermatol. 2002; 11:1-11. [PubMed: 11952823]

5. Krammer PH, Arnold R, Lavrik IN. Life and death in peripheral T cells. Natl Rev Immunol. 2007; 7:532-42.

6. Green DR, Droin N, Pinkoski M. Activation-induced cell death in T cells. Immunol Rev. 2003; 193:70-81. [PubMed: 12752672]

7. Contassot E, French LE. Targeting apoptosis defects in cutaneous T-cell lymphoma. J Invest Dermatol. 2009; 129:1059-61. [PubMed: 19369931]

8. Braun FK, Fecker LF, Schwarz C, et al. Blockade of death receptor-mediated pathways early in the signaling cascade coincides with distinct apoptosis resistance in cutaneous T-cell lymphoma cells. J Invest Dermatol. 2007; 127:2425-37. [PubMed: 17495957]

9. Wu J, Nihal M, Siddiqui J, et al. Low FAS/CD95 expression by CTCL correlates with reduced sensitivity to apoptosis that can be restored by FAS upregulation. J Invest Dermatol. 2009; 129:1165-73. [PubMed: 18923451]

10. Wu J, Wood GS. Reduction of Fas/CD95 promoter methylation, upregulation of Fas protein, and enhancement of sensitivity to apoptosis in cutaneous T-cell lymphoma. Arch Dermatol. 2011; 147:443-9. [PubMed: 21173302]

11. Klemke CD, Brenner D, Weiss EM, et al. Lack of T-cell receptor-induced signaling is crucial for CD95 ligand up-regulation and protects cutaneous T-cell lymphoma cells from activation-induced cell death. Cancer Res. 2009; 69:4175-83. [PubMed: 19435902]

12. Stutz N, Johnson RD, Wood GS. The FAS apoptotic pathway in cutaneous T-cell lymphomas: frequent expression of phenotypes associated with resistance to apoptosis. J Am Acad Dermatol. 2012; 67:1327.e1-1327.e10. [PubMed: 22884443]

13. Wu J, Salva KA, Wood GS. C-Cbl E3 ubiquitin ligase is overexpressed in cutaneous T-cell lymphoma: its inhibition promotes activation-induced cell death. J Invest Dermatol. 2015; 135:861-8. [PubMed: 25140833] 
14. Liu YC. Ubiquitin ligases and the immune response. Annu Rev Immunol. 2004; 22:81-127. [PubMed: 15032575]

15. Berndsen CE, Wolberger C. New insights into ubiquitin E3 ligase mechanism. Nat Struct Mol Biol. 2014; 21:301-7. [PubMed: 24699078]

16. Schmidt MHH, Dikic I. The Cbl interactome and its functions. Mol Cell Biol. 2005; 6:907-18.

17. Mohapatra B, Ahmad G, Nadeau S, et al. Protein tyrosine kinase regulation by ubiquitination: critical roles of Cbl-family ubiquitin ligases. Biochim Biophys Acta. 2013; 1833:122-39. [PubMed: 23085373]

18. Loeser S, Penninger JM. The ubiquitin E3 ligase Cbl-b in T-cell tolerance and tumor immunity. Cell Cycle. 2007; 6:2478-85. [PubMed: 17704644]

19. Paolino M, Penninger JM. E3 ubiquitin ligases in T-cell tolerance. Eur J Immunol. 2009; 39:233744. [PubMed: 19714573]

20. Qiao G, Zhao Y, Li Z, et al. T cell activation threshold regulated by E3 ubiquitin ligase Cbl-b determines fate of inducible regulatory T cells. J Immunol. 2013; 191:632-39. [PubMed: 23749633]

21. Salva KA, Nihal M, Wu J, et al. Analysis of protein expression in situ using multi-spectral imaging is superior to conventional immunohistochemistry (IHC): a new paradigm for patient selection for targeted therapy. J Invest Dermatol Symp Proc. 2013; 133:S169.

22. Kaltoft K, Bisballe S, Rasmussen HF, et al. A continuous T-cell line from a patient with Sézary syndrome. Arch Dermatol Res. 1987; 279:293-8. [PubMed: 3498444]

23. Starkebaum G, Loughran TP, Waters CA, et al. Establishment of an IL-2 independent, human Tcell line possessing only the p70 IL-2 receptor. Int J Cancer. 1991; 49:246-53. [PubMed: 1879969]

24. Abrams JT, Lessin S, Ghosh SK, et al. A clonal CD4-positive T-cell line established from the blood of a patient with Sézary syndrome. J Invest Dermatol. 1991; 96:31-7. [PubMed: 1987293]

25. Gootenberg JE, Ruscetti FW, Mier JW, et al. Human cutaneous T cell lymphoma and leukemia cell line produce and respond to T cell growth factor. J Exp Med. 1981; 154:1403-18. [PubMed: 6975346]

26. Kaltoft K, Bisballe S, Dyrberg T, et al. Establishment of two continuous T-cell strains from a single plaque of a patient with mycosis fungoides. In vitro Cell Dev Biol. 1992; 28A:161-7. [PubMed: 1582990]

27. Saito Y, Aoki Y, Muramatsu H, et al. Casitas B-cell lymphoma mutation in childhood T-cell acute lymphoblastic leukemia. Leuk Res. 2012; 36:1009-15. [PubMed: 22591685]

28. Lo FY, Tan YHC, Cheng HC, et al. An E3 ubiquitin ligase c-Cbl: a new therapeutic target of lung cancer in cell and animal models. Cancer. 2011; 117(23):5344-50. [PubMed: 21607942]

29. Sproul AA, Xu Z, Wilhelm M, et al. Cbl negatively regulates JNK activation and cell death. Cell Res. 2009; 19:950-61. [PubMed: 19546888]

30. Niemeyer CM, Kang MW, Shin DH, et al. Germline CBL mutations cause developmental abnormalities and predispose to juvenile myelomonocytic leukemia. Nat genet. 2010; 42:794-800. [PubMed: 20694012]

31. Ogawa S, Sanada M, Shih LY, et al. Gain-of-function c-CBL mutations associated with uniparental disomy of 11q in myeloid neoplasms. Cell Cycle. 2010; 9(6):1051-6. [PubMed: 20237427]

32. Sagrin B, Choudhary C, Crosetto N, et al. Flt3-dependent transformation by inactivating c-CBL mutations in AML. Blood. 2007; 110(3):1004-12. [PubMed: 17446348]

33. Sanada M, Suzuki T, Shih LY, et al. Gain-of-function of mutated C-CBL tumor suppressor in myeloid neoplasms. Nature. 2009; 460:904-8. [PubMed: 19620960]

34. Bacher U, Haferlach C, Schnittger S, et al. Mutations of the TET2 and CBL genes: novel molecular markers in myeloid malignancies. Ann Hematol. 2010; 89:643-52. [PubMed: 20195608]

35. Truitt L, Freywald T, DeCoteau J, et al. The EphB6 receptor cooperates with c-CBL to regulate the behavior of breast cancer cells. Cancer Res. 2010; 70:1141-53. [PubMed: 20086179]

36. Sors A, Jean-Louis F, Pellet C, et al. Down-regulating constitutive activation of the NF- B canonical pathway overcomes the resistance of cutaneous T-cell lymphoma to apoptosis. Blood. 2006; 107:2354-63. [PubMed: 16219794] 
37. Yokouchi M, Kondo T, Sanjay A, et al. Src-catalyzed phosphorylation of c-CBL leads to the interdependent ubiquitination of both proteins. J Biol Chem. 2001; 276:35185-93. [PubMed: 11448952]

38. Grivennikov SI, Greten FR, Karin M. Immunity, inflammation and cancer. Cell. 2010; 140:883-99. [PubMed: 20303878]

39. Chiorazzi N, Rai KR, Ferrarini M. Chronic lymphocytic leukemia. N Engl J Med. 2005; 352:80415. [PubMed: 15728813]

40. Ferreri AJ, Ernberg I, Copie-Bergman C. Infectious agents and lymphoma development: molecular and clinical aspects. J Intern Med. 2009; 265:421-38. [PubMed: 19298458]

41. Rajka G, Winkelmann RK. Atopic dermatitis and Sézary syndrome. Arch Dermatol. 1984; 120:834. [PubMed: 6691719]

42. Abel EA, Nickoloff BJ, Shelby DM, et al. Tumor stage mycosis fungoides in a patient treated with long-term corticosteroids for asthma and atopic-like dermatitis. J Dermatol Surg Oncol. 1986; 12:1089-93. [PubMed: 3489744]

43. Onsun N, Kural Y, Su Ö, et al. Hypopigmented mycosis fungoides associated with atopy in two children. Pediatr Dermatol. 2006; 23:493-6. [PubMed: 17014650]

44. Meyer N, Mazereeuw-Hautier J, Launay F, et al. Cutaneous T cell lymphoma complicating severe atopic dermatitis. Dermatology. 2009; 218:168-71. [PubMed: 19060456]

45. Di Lernia V, Ricci C, Grenzi L, et al. Folliculotropic mycosis fungoides in a psoriatic patient under methotrexate treatment. J Dtsch Dermatol Ges. 2009; 7:1068-70. [PubMed: 19686545]

46. Tilakaratne D, Sidhu S. Heavy metal (monoclonal) bands: a link between cutaneous T-cell lymphoma and contact allergy to potassium dichromate, nickel and cobalt? Australas J Dermatol. 2015; 56:59-63. [PubMed: 25303728]

47. Jahan-Tigh RR, Huen AO, Lee GL, Pozadzides JV, Liu P, Duvic M. Hydrochlorothiazide and cutaneous T cell lymphoma: prospective analysis and case series. Cancer. 2013; 119:825-31. [PubMed: 22952039]

48. Foo SH, Shah F, Chaganti S, et al. Unmasking mycosis fungoides/Sézary syndrome from preceding or co-existing benign inflammatory dermatoses requiring systemic therapies: patients frequently present with advanced disease and have an aggressive clinical course. Br J Dermatol. 2015 Oct 19.doi: 10.1111/bjd.14238

49. Frentz G, Olsen JH. Malignant tumours and psoriasis: a follow-up study. Br J dermatol. 1999; 140:237-42. [PubMed: 10233215]

50. Hanuksela-Svahn A, Pukkala E, Läärä E, et al. Psoriasis, its treatment, and cancer in a cohort of Finnish patients. J Invest Dermatol. 2000; 114:587-90. [PubMed: 10692122]

51. Margolis D, Bilker W, Hennessy S, et al. The risk of malignancy associated with psoriasis. Arch Dermatol. 2001; 137:778-83. [PubMed: 11405770]

52. Gelfand JM, Berlin J, Van Voorhees A, et al. Lymphoma rates are low but increased in patients with psoriasis. Arch Dermatol. 2003; 139:1425-9. [PubMed: 14623702]

53. Mehrany K, El-Azhary RA, Bouwhuis SA, et al. Cutaneous T-cell lymphoma and atopy: is there an association? Br J Dermatol. 2003; 149:1013-7. [PubMed: 14632807]

54. Gelfand JM, Shin DB, Neimann AL, et al. The risk of lymphoma in patients with psoriasis. J Invest Dermatol. 2006; 126:2194-201. [PubMed: 16741509]

55. Ekström Smedby K, Vajdic CM, Falster M, et al. Autoimmune disorders and risk of non-Hodgkin lymphoma subtypes: a pooled analysis within the InterLymph consortium. Blood. 2008; 111:4029-38. [PubMed: 18263783]

56. Brauchli YB, Jick SS, Miret M, et al. Psoriasis and risk of incident cancer: an inception cohort study with a nested case-control analysis. J Invest Dermatol. 2009; 129:2604-12. [PubMed: 19440219]

57. Pouplard C, Brebaut E, Horreau C. Risk of cancer in psoriasis: a systematic review and metaanalysis of epidemiological studies. J Eur Acad Dermatol Venereol. 2013; 27:36-46. [PubMed: 23845151]

58. Legendre L, Barnetche T, Mazereeuw-Hautier J, et al. Risk of lymphoma in patients with atopic dermatitis and the role of topical treatment: a systematic review and meta-analysis. J Am Acad Dermatol. 2015; 72:992-1002. [PubMed: 25840730] 
59. Chiesa Fuxench ZC, Shin DB, Beatty AO, et al. The risk of cancer in patients with psoriasis: a population-based cohort study in the Health Improvement network. JAMA Dermatol. 2016; 152:282-90. [PubMed: 26676102]

60. Wu J, Salva KA, Stutz N, et al. Quantitative gene analysis of methylation and expression (QGAME) in fresh or fixed cells and tissues. Exp Dermatol. 2014; 23:304-9. [PubMed: 24646432]

61. Salva KA, Bennett D, Longley J, et al. Multispectral imaging approach to the diagnosis of a CD20+ cutaneous T-cell lymphoproliferative disorder (CTCLPD): a case report. Am J Dermatopathol. 2015; 37:116-21. 


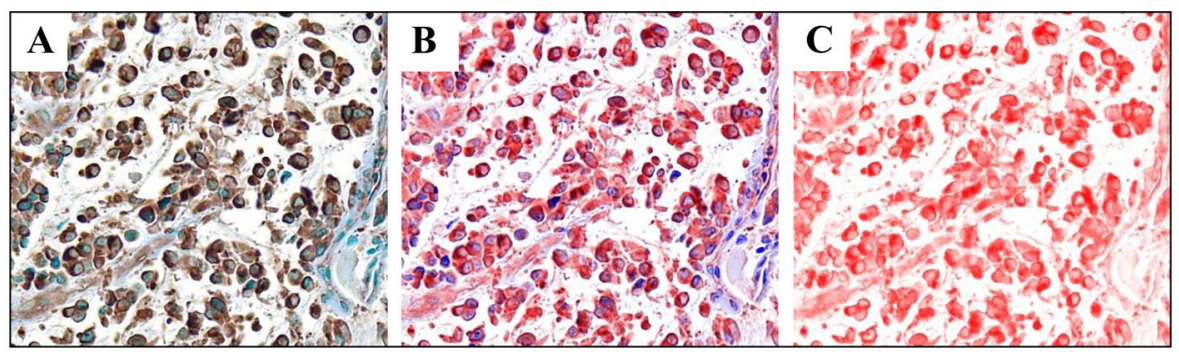

Figure 1.

Representative images of protein visualization with multispectral imaging technology, showing c-CBL expression in lesional skin of patch/plaque mycosis fungoides. Multispectral imaging systems can unmix routine immunohistochemical (IHC) images into individual components. The unique spectral curves of each chromogen - here, diaminobenzidine (brown) and the nuclear counterstain methylene blue (blue) - are used to convert the standard light microscopic image (A) into a computer-generated pseudo-colored composite (B). The pseudo-color red was used-assigned to depict c-CBL expression, which is shown unmixed (without the counterstain) to observe the full extent of stain intensity $(\mathbf{C})$. As outlined in detail in Materials and Methods, the amount of target signal (here, the intensity of the red pseudo-color) is displayed as average optical density (OD) per cell. Original magnification of all images: $\mathrm{x} 400$. 


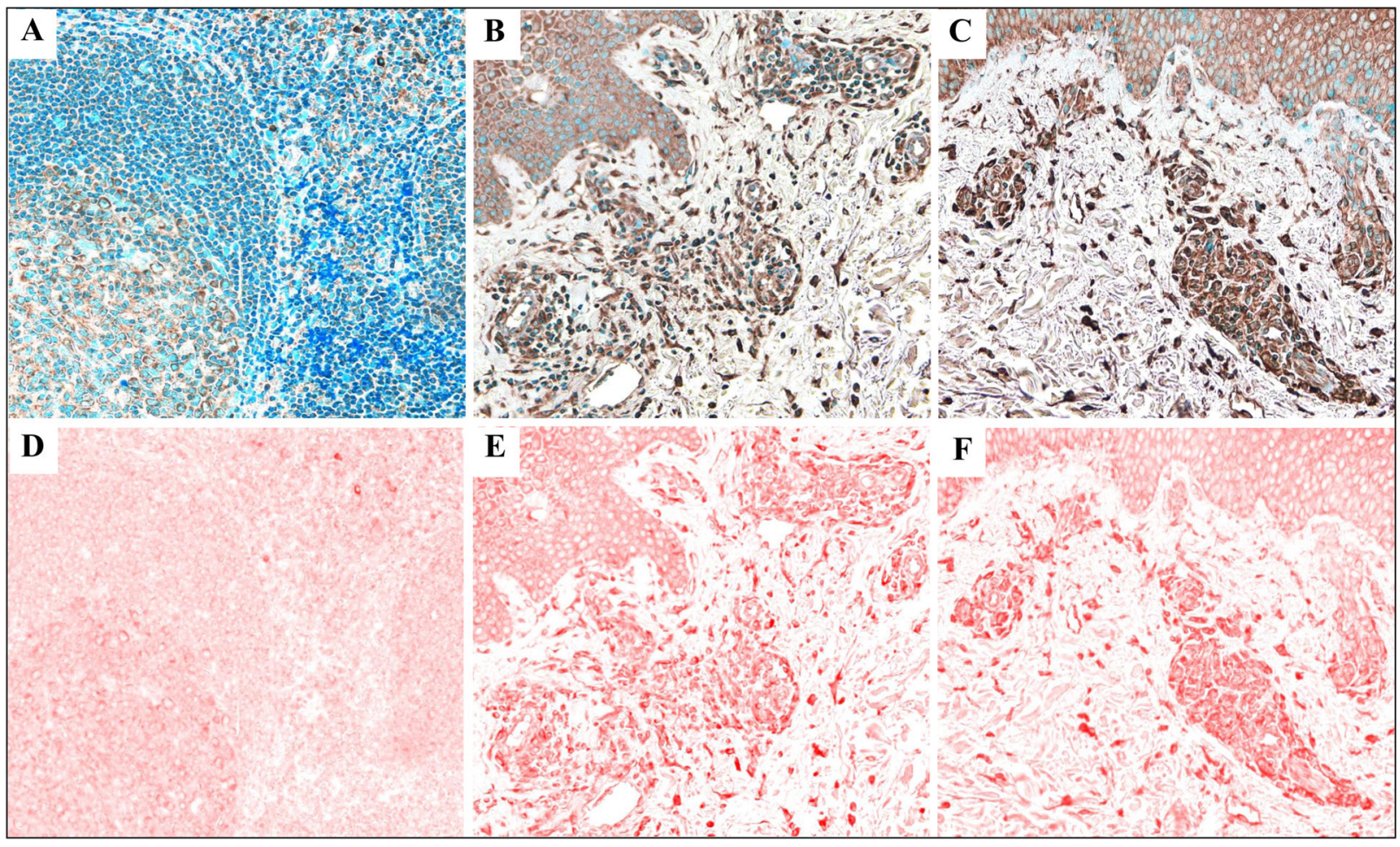

Figure 2.

Immunohistochemical images of the c-CBL stain (brown) in reactive tonsil (A), atopic dermatitis $(\mathbf{B})$, and patch/plaque-stage $\mathrm{MF}(\mathbf{C})$ and corresponding multispectral images of cCBL protein shown in the pseudo-color red (D-F). Original magnification of all images: $\mathrm{x} 200$. 


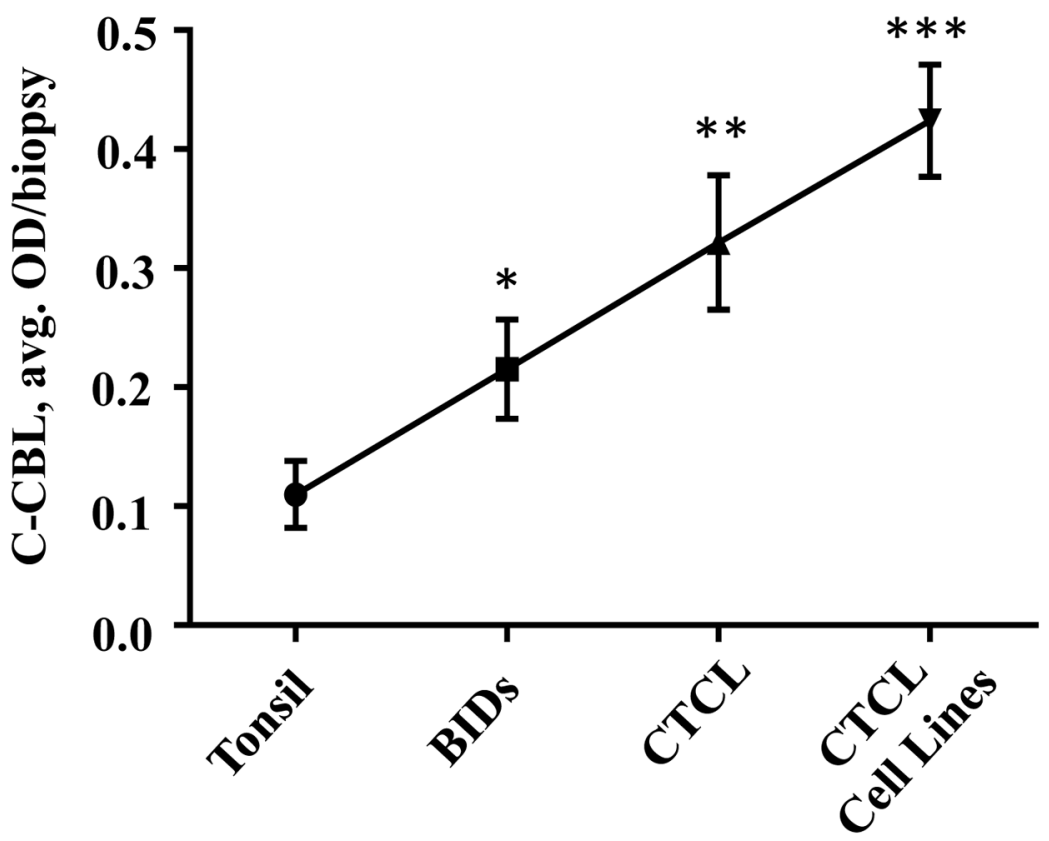

Figure 3.

Quantitative MIA-based assessment of c-CBL expression across the spectrum of secondary lymphoid tissue (reactive tonsil tissue, 5 cases), BIDs (47 cases), CTCL lesional skin (18 cases) and CTCL cell lines (5 distinct cell lines). $* \mathrm{p}<0.05$ as compared to tonsil, ** $\mathrm{p}<$ 0.05 as compared to tonsil as well as BIDs, $* * * \mathrm{p}<0.05$ as compared to tonsil, BIDs and CTCL lesions. 


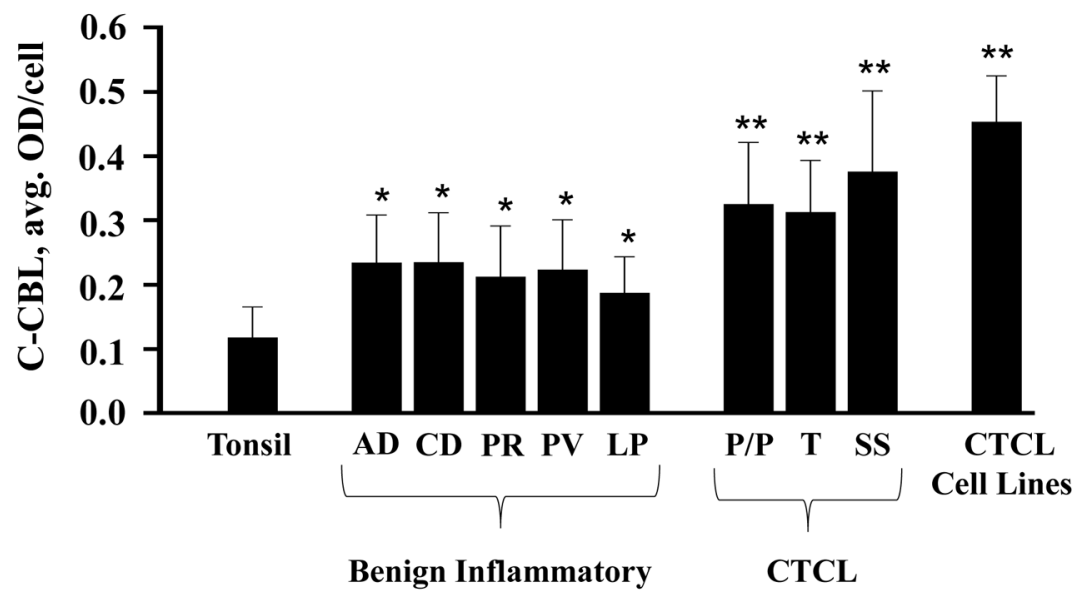
Dermatoses

Figure 4.

Quantitative assessment of C-CBL expression in various types of specimens based on specific clinical diagnoses. $\mathrm{AD}$, atopic dermatitis; $\mathrm{CD}$, contact dermatitis; $\mathrm{PR}$, pityriasis rosea; PV, psoriasis vulgaris; LP, lichen planus; P/P, patch/plaque-stage mycosis fungoides; T, tumor-stage mycosis fungoides; SS, Sézary syndrome; CTCL: cutaneous T-cell lymphoma, $* \mathrm{p}<0.05$ as compared to tonsil, $* * \mathrm{p}<0.05$ as compared to tonsil as well as BIDs. 


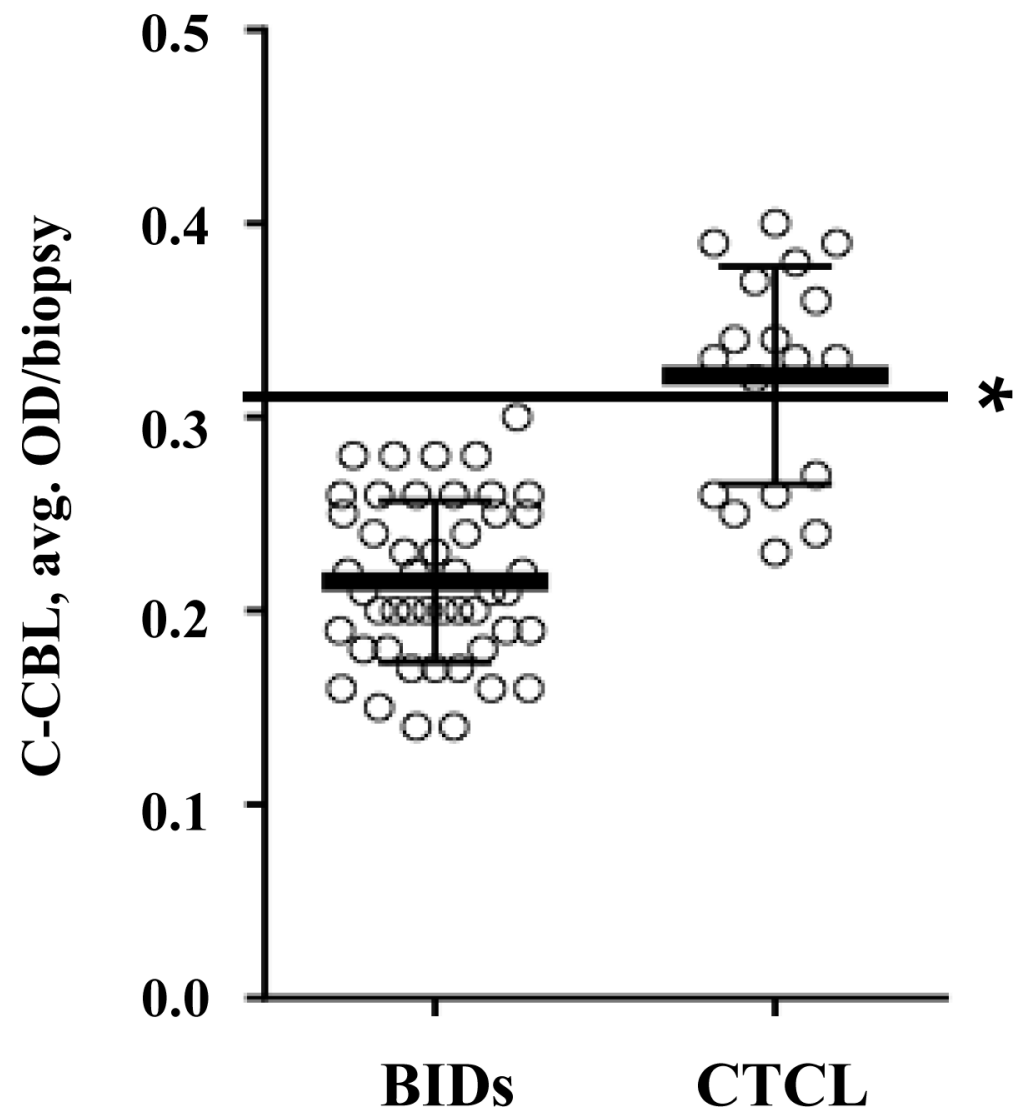

Figure 5.

C-CBL expression in lesional biopsies of patients with BIDs (47 cases) versus CTCL (18 cases). The protein expression values recorded in BIDs were below the threshold of 0.32 OD/biopsy, which is indicated by the horizontal line (*). The bars represent the mean and \pm 1 SD. 


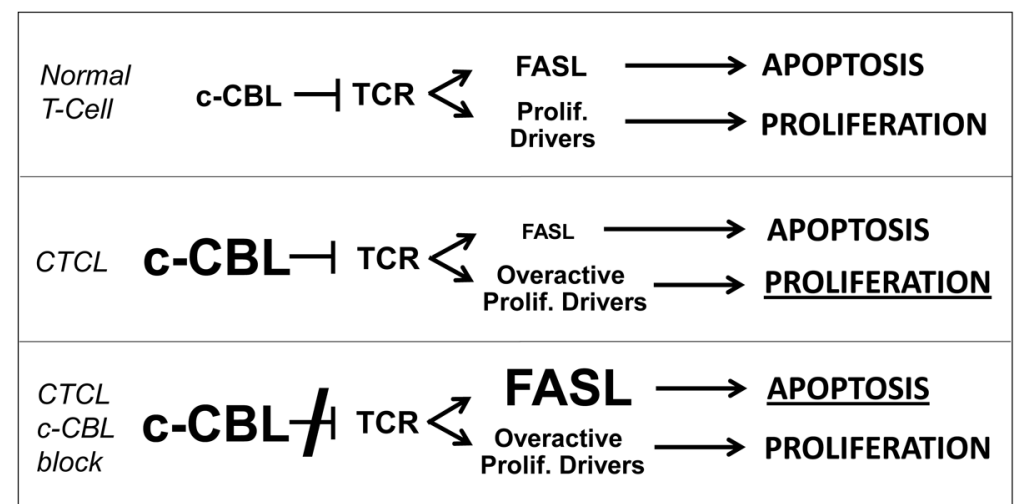

Figure 6.

Schematic depiction of c-CBL blockade as a strategy to overcome the resistance of CTCL to TCR-mediated apoptosis. Normal T cells expressing adequate amounts of c-CBL maintain a balance between apoptosis and proliferation (top panel). In CTCL, the constitutive overactivity of both c-CBL as well as proliferative drivers results in diminished apoptosis and unchecked proliferation (middle panel; the dominant effect is indicated by a larger font size and underlining). Blocking of c-CBL restores TCR-induced FASL upregulation, thereby eliciting massive apoptosis which overcomes proliferation (bottom panel). 


\section{Table 1}

Summary of clinical diagnoses and demographic data.

\begin{tabular}{|c|c|c|c|c|}
\hline \multicolumn{2}{|c|}{ Clinical diagnosis } & \multirow{2}{*}{$\frac{\text { Number of cases }}{*}$} & \multirow{2}{*}{$\frac{\text { Mean age }[ \pm \mathrm{SD}] \text { at time of biopsy }}{\text { not available }}$} & \multirow{2}{*}{$\frac{\text { Gender ratio }[\mathbf{M : F}]}{\text { not available }}$} \\
\hline Secondary lymphoid tissue & Reactive tonsil & & & \\
\hline \multirow{5}{*}{ BIDs } & Atopic dermatitis & 10 & $56[ \pm 16]$ & $6: 4$ \\
\hline & Contact dermatitis & 11 & $52[ \pm 17]$ & $8: 3$ \\
\hline & Pityriasis rosea & 8 & $38[ \pm 14]$ & $4: 4$ \\
\hline & Psoriasis vulgaris & 8 & $51[ \pm 23]$ & $5: 3$ \\
\hline & Lichen planus & 10 & $62[ \pm 16]$ & $4: 6$ \\
\hline \multirow{3}{*}{ CTCL } & MF patch/plaque & 11 & \multirow{3}{*}{$63[ \pm 12]$} & \multirow{3}{*}{$9: 9$} \\
\hline & MF tumor & 4 & & \\
\hline & SS skin & 3 & & \\
\hline \multirow{5}{*}{ CTCL cell lines } & $\mathrm{MyLa}^{\mathrm{a}}$ & \multirow{5}{*}{5} & \multirow{5}{*}{$\mathrm{n} / \mathrm{a}^{* * *}$} & \multirow{5}{*}{$3: 2$} \\
\hline & $\operatorname{SeAx}{ }^{b}$ & & & \\
\hline & Hut $78^{b}$ & & & \\
\hline & $\mathrm{SZ}^{\mathrm{b}}$ & & & \\
\hline & $\mathrm{HH}^{\mathrm{c}}$ & & & \\
\hline
\end{tabular}

* One biopsy per patient was assessed in 64 cases. Two biopsies corresponding to two different lesion types (plaque and tumor) were evaluated in one patient with tumor-stage MF.

Tonsil tissue from 5 distinct individuals was obtained as de-identified specimens. Human CTCL cell lines were originally derived from an MF plaque ${ }^{b}$ and from the peripheral blood of patients with SS ${ }^{c}$ or with an unspecified leukemic-stage CTCL $d$.

Mean age $[ \pm \mathrm{SD}]$ of patients at time of cell harvest: $66[ \pm 11]$.

BIDs: benign inflammatory dermatoses; CTCL: cutaneous T-cell lymphoma; MF: mycosis fungoides; SS: Sézary syndrome. 